\title{
SUPRACONDYLAR FRACTURE OF THE HUMERUS IN CHILDREN: FIXATION WITH TWO CROSSED KIRSCHNER WIRES
}

Roni Azevedo Carvalho', Nelson Franco Filho ${ }^{2}$, Antonio Batalha Castello Neto ${ }^{3}$, Giulyano Dias Reis ${ }^{3}$, Marcos Pereira Dias ${ }^{3}$

\section{ABSTRACT}

Objective: To analyze and present the surgical results from unstable supracondylar fractures of the humerus in children, treated by means of reduction and percutaneous fixation using two crossed Kirschner wires. Methods: A cross-sectional study was conducted on 20 children, taking into consideration sex, age at the time of the fracture, age at the time of the assessment, side affected, type and mechanism of trauma, postoperative complications and radiographic and clinic variables. Results: Ten fractures were observed in the left arm and ten in the right arm. The age at the time of the fracture ranged from 2 to 13 years (mean: $5.9 \pm 2.48$ years). Three fractures were classified as type II and 17 as type III. The length of follow-up ranged from four months to three years. Baumann's angle ranged from 69 to 100 (mean: 78.3) and cubitus varus was observed in four patients (values ranging from 84 to 100). According to the modified Flynn's criteria, 20 cases presented satisfactory outcomes: 17 excellent $(85 \%)$, two good $(10 \%)$ and one regular (5\%). Two patients presented limited range of motion, two had paresthesia in the cubital region and one had transient neuropraxia of the ulnar nerve for six weeks. Conclusion: Percutaneous fixation with two crossed Kirschner wires leads to good results when carried out under direct viewing and with isolation of the ulnar nerve.

Keywords - Child; Humerus Fractures; Bone Wires; Fracture Fixation

\section{INTRODUCTION}

Of the upper limbs in children, the elbow is the second most common site of occurrence of fractures, surpassed only by forearm fractures. Around $85 \%$ of elbow fractures in children occur in the distal humerus, and of these, 55 to $75 \%$ are supracondylar fractures, accounting for $3 \%$ of all fractures in children ${ }^{(1-4)}$.

Supracondylar humerus fractures are caused by direct or indirect low-kinetic energy traumas, such as falls, which makes the occurrence of comminution, bone exposure or association with other fractures less frequent ${ }^{(1-4)}$.

Due to the anatomical characteristics of this region, and the variations in fractured fragments, immediate complications (vascular-nerve injuries, compartment syndrome) and late complications (vicious consolidation and angular deformities) can arise ${ }^{(5-8)}$.

Despite the various types of treatment, high morbidity and complications related to this type of fracture make treatment urgent and essential ${ }^{(1)}$.

Treatment with closed reduction, associated with plaster cast immobilization, has been gradually abandoned, particularly due to the higher complication rate, such as loss of reduction, compartment syndrome, and long hospitalization periods ${ }^{(9-11)}$.

The objective of this paper is to analyze and present the results obtained with the treatment of unstable supracondylar humerus fractures in children, who underwent closed reduction surgery and percutaneous fixation using two crossed Kirschner wires.

1 - Physician; Head, Department of Pediatric Orthopedics, Hospital Universitário de Taubaté - Taubaté, SP, Brazil.

2 - Physician; Master's degree; Doctor's degree; Head, Orthopedics and Traumatology Clinic, Hospital Universitário de Taubaté - Taubaté, SP, Brazil.

3 - Physician; Resident in Orthopedics and Traumatology, Hospital Universitário de Taubaté - Taubaté, SP, Brazil.

Study conducted at the Orthopedics and Traumatology Clinic in Taubaté, SP.

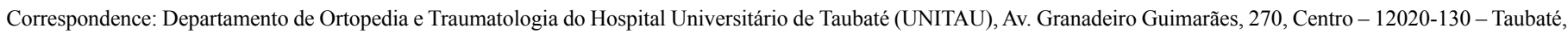
SP, Brazil. Email: ortopedia@hutaubate.com.br

Received for publication: 12/3/2011, accepted for publication: 4/27/2012.

The authors declare that there was no conflict of interest in conducting this work 


\section{METHODS}

Forty-six patients were identified, who had unstable, closed (Gartland types II and III) ${ }^{(12)}$ supracondylar humerus fracture, and who underwent closed reduction and percutaneous fixation using two crossed Kirschner wires, from April 2008 to August 2010.

The sample analyzed consisted of 20 patients; chil- dren with any comorbidities that would interfere in the consolidation of the fracture were excluded, as well as children with neurovascular injury, association with other fractures, and exposed fractures (Table 1).

The following variables were taken into account: sex, age at the time of the fracture and of the assessment, date of surgery, side affected, mechanism and type of fracture (classification), postoperative complications and

Table 1 - Database of patients assessed.

\begin{tabular}{|c|c|c|c|c|c|c|c|c|c|}
\hline & Gender & $\begin{array}{c}\text { Current } \\
\text { age }\end{array}$ & $\begin{array}{l}\text { Age at } \\
\text { surgery }\end{array}$ & Surgery date & Follow-up (years) & Side & Gartland & Post-surgery complications & Baumann \\
\hline 1 & M & 6 & 4 & 04/27/2008 & 3.41 & L & 3 & None & 69 \\
\hline 2 & M & 10 & 8 & 07/09/2008 & 3.21 & L & 3 & None & 73 \\
\hline 3 & $\mathrm{~F}$ & 7 & 5 & 09/19/2008 & 3.01 & L & 3 & None & 77 \\
\hline 4 & M & 5 & 3 & $11 / 21 / 2008$ & 2.84 & L & 3 & Cubitus varus & 84 \\
\hline 5 & $\mathrm{~F}$ & 5 & 3 & $12 / 04 / 2008$ & 2.80 & $\mathrm{R}$ & 3 & Cubitus varus & 90 \\
\hline 6 & M & 8 & 6 & 01/16/2009 & 2.68 & L & 3 & None & 71 \\
\hline 7 & M & 6 & 4 & 01/16/2009 & 2.68 & $\mathrm{R}$ & 3 & Cubitus varus; flexion 100 & 100 \\
\hline 8 & $\mathrm{~F}$ & 8 & 6 & 02/21/2009 & 2.58 & L & 3 & Cubitus varus & 88 \\
\hline 9 & M & 4 & 2 & 02/24/2009 & 2.58 & $\mathrm{R}$ & 3 & None & 78 \\
\hline 10 & M & 9 & 7 & 02/24/2009 & 2.58 & L & 2 & None & 78 \\
\hline 11 & M & 9 & 8 & 03/02/2009 & 2.56 & $\mathrm{R}$ & 3 & None & 70 \\
\hline 12 & $\mathrm{~F}$ & 7 & 6 & 04/23/2009 & 2.42 & L & 3 & None & 79 \\
\hline 13 & $\mathrm{~F}$ & 9 & 8 & 07/20/2009 & 2.18 & $\mathrm{R}$ & 3 & None & 77 \\
\hline 14 & M & 10 & 9 & 07/22/2009 & 2.17 & L & 3 & None & 79 \\
\hline 15 & M & 6 & 5 & 09/18/2009 & 2.01 & $\mathrm{R}$ & 3 & None & 75 \\
\hline 16 & M & 6 & 5 & 01/23/2010 & 1.66 & $\mathrm{R}$ & 3 & None & 69 \\
\hline 17 & M & 5 & 5 & 05/22/2010 & 1.34 & $\mathrm{R}$ & 3 & Cubital paresthesia & 78 \\
\hline 18 & M & 13 & 13 & 07/29/2010 & 1.15 & L & 2 & Cubital paresthesia; flexion 100 & 72 \\
\hline 19 & $\mathrm{~F}$ & 3 & 3 & 07/30/2010 & 1.15 & $\mathrm{R}$ & 2 & Ulnar neuropraxia & 80 \\
\hline 20 & M & 6 & 6 & 08/21/2010 & 1.09 & $\mathrm{R}$ & 3 & None & 76 \\
\hline
\end{tabular}


radiographic variables (Baumann's angle) ${ }^{(13)}$.

With the consent of their respective legal guardians, and after revision of all medical data, the children were submitted to clinical and radiological analysis.

According to the protocol established at our clinic, all the patients initially underwent clinical evaluation, followed by analgesics and plaster cast immobilization, with no attempt at reduction. After preliminary evaluation, the patients were sent to the surgical center.

After general inhalational anesthetics with intubation, in the horizontal dorsal position, the reduction operation was then performed with the elbow extended and the forearm supinated, with longitudinal traction and contraction to recover the length, and clinical alignment of the load angle. Subsequently, the edges of both fragments were aligned, with hyperextension and supination as needed. At this point, maneuvers were performed in valgus or in varus to correct medial or lateral dislocations. When these two deviations were corrected, the angle of the distal fragment was corrected, flexing the elbow while pushing the distal fragment anteriorly.

After asepsis and antisepsis, the fracture was fixed with two smooth, crossed Kirschner wires, passing through the medial and lateral epicondyles. Before passing the wires, a small skin incision was made, of around $1 \mathrm{~cm}$, to enable insertion of the wire without damaging the adjacent soft tissues due to torque, and to protect the ulnar nerve from injury. In this fixation, the wires were positioned at an angle of between 30 and $40^{\circ}$. The reduction was always checked through a radioscopy of the elbow, in the anteroposterior (with the elbow in maximum extension and supination) and lateral (with shoulder rotated externally) views. The Kirschner wires were cut and left outside the skin. The wound was dressed, and a full-arm cast was applied, with the elbow flexed at an angle of $90^{\circ}$ and the forearm in neutral rotation. Active and passive finger exercises were prescribed from the time of arrival at the ward, and the upper limb that had been operated on was kept suspended during hospitalization. Patients were discharged within 24 to 48 hours, with an initial follow-up visit within seven to ten days, and a second within 14 to 17 days. The cast and the Kirschner wires were removed between the fourth and sixth week after surgery, when mobilization was prescribed to recover the range of motion. Subsequent follow-up visits were held at every 30 days until outpatient discharge (Figure 1).

Patients were submitted to radiography analysis through measurement of the Baumann's angle ${ }^{(13)}$, and clinical analysis according to the modified criteria proposed by Flynn et $\mathrm{al}^{(14)}$ for fracture consolidation, range of motion, and post-surgical neurovascular complications.

Elbows with Baumann's angle under $64^{\circ}$ were considered in valgus ${ }^{(13)}$, and those with Baumann's angle over $82^{\circ}$ were considered cubitus varus ${ }^{(15-22)}$.

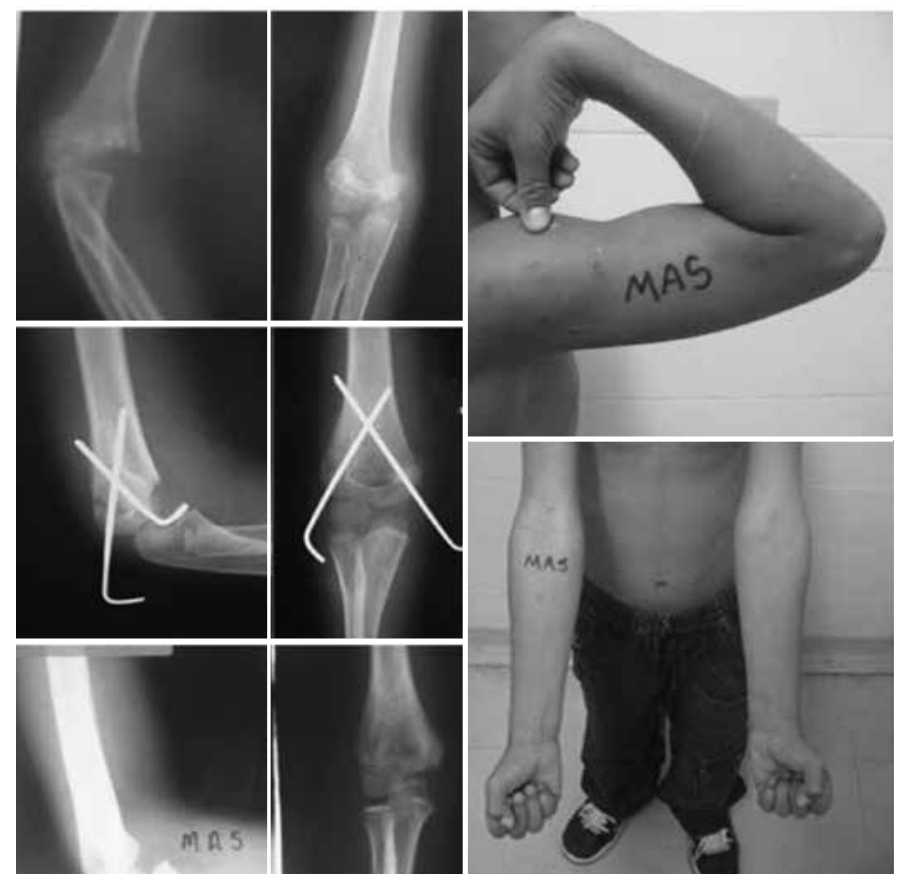

Figure 1 - Example of the results obtained.

\section{RESULTS}

Twenty children were observed, with ten fractures of the right elbow, and ten of the left elbow. The trauma mechanism was indirect, with extended limb in all cases. The children's ages at the time of fracture ranged from two to 13 years (average of $5.9 \pm 2.48$; median 5.5 years). The children's ages at the time of assessment ranged from three to 13 years (average of $7 \pm 2.53$; median 6.5 years). The Gartland classification $^{(12)}$ was used, resulting in three fractures being classified as type II and 17 as type III. The follow-up period ranged from four months to three years.

Baumann's angle measured through X-ray ranged from 69 to 100 (average of 78.3); cubitus varus was 
observed in four patients (ranging from 84 to 100). According to the modified criteria established by Flynn et $\mathrm{al}^{(14)}, 20$ cases were satisfactory, with no unsatisfactory cases. Of the satisfactory results, 17 were excellent (85\%), two were good (10\%), and one fair $(5 \%)$. The fractures of all patients were completely consolidated within the expected period, with no case of delay in consolidation or pseudarthrosis. Two patients had reduced range of motion, with $100^{\circ}$ flexion in both cases. Two children had cubital paresthesia due to extrinsic compression, which was solved by replacing the cast. One child had transient neuropraxia of the ulnar nerve for six weeks, which disappeared when the wires were removed.

\section{DISCUSSION}

Supracondylar humerus fracture in children is an urgent condition, requiring rapid diagnosis and treatment, particularly due to the serious vascular and nerve complications associated with this injury ${ }^{(1,4,5-8,16,23-25)}$. The surgeon's objective is to obtain anatomical reduction and reestablish function as soon as possible. The higher the level of instability, the higher the complication rate ${ }^{(24)}$. Thorough neurological examination and palpation of the distal peripheral pulse are imperative during the initial analysis of all patients.

Percutaneous fixation is popular, and was described by Judet and Swenson as an osteosynthesis technique based on the work by Miller (1939) apud Fumo et $\mathrm{al}^{(26)}$ which recommends this method for the treatment of T-shaped injuries; its widespread use is due to a series of advantages, including low cost, safety, efficiency and minimal hospitalization times.

In our case series, we observed a distribution per sex (male-female) similar to that observed in the literature $(2.3: 1)$, and there was no predominance in relation to affected side. The patient's age at the time of fracture was also equally similar: 5.9 years ${ }^{(2,4,26-29)}$.

The development of compartment syndrome is the most feared complication of this type of injury. Nerve injuries, such as neuropraxia, are relatively common, accounting for between 6 and $16 \%$ of all complications $^{(2,3,26-29)}$. Lesion of the ulnar nerve, although rare $(4.3 \%)$, is usually reversible, and is most commonly related to untimely treatment and edema in the region, which makes it difficult to feel and identify the anatomical accidents. One case $(5 \%)$ of percutaneous fixation by extrinsic compression of the wire was observed, which was resolved when the percutaneous wires were removed in the sixth week. Also, two cases (10\%) had cubital paresthesia, which were solved after replacement of the plaster cast. Brauer et $\mathrm{al}^{(29)}$ and Woratanarat et al ${ }^{(27)}$ stated that iatrogenic lesions of the ulnar nerve are two to four times more frequent with cross-fixation, suggesting fixation with two parallel, lateral wires.

Authors who advocate the use of crossed wires defend the high rate of satisfactory results, as a consequence of the greater stability with restored anatomy, due to the strength applied medially through elastic deformation of the wire, known as the "spring effect"(26). A reduced arc of flexion-extension was observed in two patients $(10 \%)$, who had $100^{\circ}$ flexion at the time of assessment. It is believed that the short follow-up period of these patients (one year and six months, and two years and six months) is responsible for the high reduction rate of the observed flexion-extension, since mobility can be recovered partially or totally within a period of up to four years ${ }^{(14)}$.

Cubitus varus is considered the most common late complication in this type of fracture, presenting an incidence of $20 \%$ in our series. Other authors who used closed reduction and percutaneous fixation reported lower rates of around $10 \%{ }^{(1,3-6,14-18,22,25,27-29)}$. The initial deviation and ligamentotaxis are the main factors mechanically influencing the final result of the fracture. The lateral ligaments are firmer in pronation and more relaxed in supination ${ }^{(18,26)}$. Closed reduction associated with plaster cast is related to a higher incidence of varus deformity. Despite anatomical reduction, rotational deformity of the distal fragment may occur when the wires are not positioned in the same plane, more commonly when one of the wires is located anterior to the other ${ }^{(1,2,4,26-29)}$. Despite the higher varus incidence in the present study, the results were considered satisfactory according to Flynn et $\mathrm{al}^{(14)}$.

\section{CONCLUSION}

Through this study, it is concluded that percutaneous fixation with crossed wires for unstable supracondylar humerus fractures in children, when performed with direct visualization and isolation of the ulnar nerve, gives good results. 


\section{REFERENCES}

1. Rouede RS, Giordano V, Amaral NP. Tratamento cirúrgico das fraturas supracondilianas desviadas do úmero na criança: análise dos resultados de 20 casos. Rev Bras Ortop. 2001;36(4):105-10.

2. Cheng JC, Shen WY. Limb fracture pattern in different pediatric age groups: a study of 3,350 children. J Orthop Trauma. 1993;7(1):15-22.

3. Canale ST. Fraturas e luxação em crianças. Canale ST. Cirurgia ortopédica de Campbell. 10a. São Paulo: Manole; 2006. In: p. 1437-53.

4. Amatuzzi MM, Zoppi Filho A, Montenegro NB. Fratura supracondiliana do úmero em crianças: estudo de 90 casos operados Rev Bras Ortop. 1997;32(6): 437-42.

5. Hungria Neto JS, Fregoneze M, Bezerra MJC, Mercadante MT, Teixeira AA Yoneda T. Fraturas supracondilianas do úmero nas crianças: avaliação do resultado do tratamento cirúrgico. Rev Bras Ortop. 1996;31(7):575-83.

6. Lal GM, Bhan S. Delayed open reduction for supracondylar fractures of the humerus. Int Orthop. 1991;15(3):189-91.

7. Nacht JL, Ecker ML, Chung SM, Lotke PA, Das M. Supracondylar fractures of the humerus in children treated by closed reduction and percutaneous pinning. Clin Orthop Relat Res. 1983;(177):203-9.

8. Wilkins KE. Conduta operatória nas fraturas supracondilianas. Clin Ortop Am North. 1990;21:269-89.

9. Blount WP. Fractures in children. Baltimore: Williams e Wilkins; 1955.

10. Boyd DW, Aronson DD. Supracondylar fractures of the humerus: a prospective study of percutaneous pinning. J Pediatr Orthop. 1992;12(6):789-94.

11. Sutton WR, Greene WB, Georgopoulos G, Dameron TB Jr. Displaced supracondylar humeral fractures in children. A comparison of results and costs in patients treated by skeletal traction versus percutaneous pinning. Clin Orthop Relat Res. 1992;(278):81-7.

12. Gartland JJ. Management of supracondylar fractures of the humerus in children. Surg Gynecol Obstet. 1959;109(2):145-54.

13. Baumann E. On the treatment of fractures of the elbow joint. Langen- beks Arch Klin Chir. 1960;295-300.

14. Flynn JC, Matthews JG, Benoit RL. Blind pinning of displaced supracondylar fractures of the humerus in children. Sixteen years' experience with long-term follow-up. J Bone Joint Surg Am. 1974;56(2):263-72.

15. Terra DL, Santos MHB, Malheiros DS, Lima CLFA, Cunha FM. Nova abordagem no tratamento da fratura supracondilar do úmero, instável, em crianças e adolescentes. Rev Bras Ortop. 2005;40(1/2):42-51.
16. Keenan WN, Clegg J. Variation of Baumann's angle with age, sex, and side: implications for its use in radiological monitoring of supracondylar fracture of the humerus in children. J Pediatr Orthop. 1996;16(1):97-8.

17. Köberle $G$. Prevenção de cúbito varo e cúbito valgo na fratura supracondiliana do úmero. Rev Bras Ortop. 2003;38(10):568-80.

18. D'Ambrosia RD. Supracondylar fractures of humerus--prevention of cubitus varus. J Bone Joint Surg Am. 1972;54(1):60-6.

19. O'Hara LJ, Barlow JW, Clarke NM. Displaced supracondylar fractures of the humerus in children. Audit changes practice. J Bone Joint Surg Br. 2000;82(2):204-10.

20. Mubarak SJ, Carroll NC. Volkmann's contracture in children: aetiology and prevention. J Bone Joint Surg Br. 1979;61(3):285-93.

21. Royce RO, Dutkowsky JP, Kasser JR, Rand FR. Neurologic complications after K-wire fixation of supracondylar humerus fractures in children. J Pediatr Orthop. 1991;11(2):191-4.

22. Worlock P. Supracondylar fractures of the humerus. Assessment of cubitus varus by the Baumann angle. J Bone Joint Surg Br. 1986;68(5):755-7.

23. Jones ET, Louis DS. Median nerve injuries associated with supracondylar fractures of the humerus in children. Clin Orthop Relat Res. 1980;(150):181-6

24. Gruber MA, Hudson OC. Supracondylar fracture of the humerus in childhood. End-result study of open reduction. J Bone Joint Surg Am. 1964;46:1245-52.

25. Pirone AM, Graham HK, Krajbich JI. Management of displaced extension-type supracondylar fractures of the humerus in children. J Bone Joint Surg Am. 1988;70(5):641-50.

26. Fumo C, Bongiovanni RR, Dobashi ET, Pascarelli L, Righi LCS. Fraturas supracondilianas de úmero na infância. Arq Bras Cien Saúde. 2009;35(1):50-56

27. Woratanarat $P$, Angsanuntsukh $C$, Rattanasiri S, Attia J, Woratanarat T, Thakkinstian A. Meta-analysis of pinning in supracondylar fracture of the humerus in children. J Orthop Trauma. 2012;26(1):48-53.

28. Slobogean BL, Jackman H, Tennant S, Slobogean GP, Mulpuri K. latrogenic ulnar nerve injury after the surgical treatment of displaced supracondylar fractures of the humerus: number needed to harm, a systematic review. J Pediatr Orthop. 2010;30(5):430-6

29. Brauer CA, Lee BM, Bae DS, Waters PM, Kocher MS. A systematic review of medial and lateral entry pinning versus lateral entry pinning for supracondylar fractures of the humerus. J Pediatr Orthop. 2007;27(2):181-6. 